\title{
A note on responses to ethyl alcohol before and after smoking ${ }^{1}$
}

\author{
SANDRA MARTIN AND ROSE MARIE PANGBORN 2 \\ UNIVERSITY OF CALIFORNIA, DAVIS
}

\begin{abstract}
Differential sensitivity was measured before and after smoking a cigarette by 10 smokers, using 10 nonsmokers as controls. Stimuli consisted of reagent grade ethanol in eight concentrations ranging from $4 \%$ to 12\%. No significant differences were observed between smokers and nonsmokers or before vs after smoking, although slightly higher overall correct responses and correspondingly smaller inds were obtained for the nonsmokers. No practice affects were noted among the control group between the first and second set of samples. The findings confirm previous results which had been recently questioned.
\end{abstract}

Previously we reported that no significant differences in inds for taste, odor, and tactile stimuli were observed between seven smokers and six nonsmokers or between before vs immediately after smoking the first cigarette of the day (Pangborn et al, 1967). Subsequently, Moncrieff (1968) commented at length on these unexpected conclusions, finding them unreconcilable with those of others (Moncrief, 1968, Krut et al, 1961; Kaplan et al, 1964) His justifiable reasoning was that variations in experimental methods among laboratories contributed to these differences, as well as the numbers of Ss used (1 smoker, 2 nonsmokers; 79 smokers, 77 nonsmokers; 34 smokers, 40 nonsmokers, respectively).

As part of an ongoing research project on oral evaluation of solutions of ethyl alcohol (Martin, 1970), we had occasion to include responses before and after smoking, which are reported herein. It was of particular interest to us to compare alcohol sensitivity among smokers because the substance elicits simultaneous olfactory, gustatory, thermal, and pain sensations when placed in the oral cavity. Liebmann \& Panettiere (1957) indicated that the great majority of consumers of blended whiskies were more strongly influenced by the tactile than by the olfactory properties of the beverage, expressing their objections in terms of "raw, rough, burning, strong, or heavy." This is not surprising in view of neurophysiological evidence that both the corda tympani nerve and the trigeminal part of the lingual nerve respond to application of alcohol to the tongue (Hellekant, 1967).
If there is validity in the hypothesis that the combustion products from tobacco form a layer over the mucosal surfaces of the oral cavity, preventing stimuli from coming into contact with the receptor sites, one would expect smokers to be less sensitive to the multiple stimulation of alcohol than nonsmokers.

\section{METHOD}

Ten cigarette smokers $\left(60^{\circ}, 49\right)$ and 10 nonsmokers $(4 \delta, 68)$ ranging in age from 22 to 50 years participated. Four smokers normally consumed at least 1 pack a day, not exceeding $1 \frac{1}{2}$ packs, and the other six smokers ranged from 4 to 15 cigarettes a day. Smokers were requested to refrain from smoking on the previous night so that the test cigarette would be the first of the day. Ss first evaluated a set of eight pairs of ethanol, then were given a popular brand of filtered cigarettes and instructed to smoke $45 \mathrm{~mm}$ in another room. They did not inhale. Immediately after smoking, the $S$ washed his hands, returned to the test booth, and evaluated a second set of eight pairs of ethanol, differing from the first only in order of presentation of the samples. The nonsmokers, who served as controls, received the first set of samples, followed by a $10-\mathrm{min}$ rest, then tested the second set. Of the $20 \mathrm{Ss}, 17$ ( 8 nonsmokers and 9 smokers) consumed wine and beer frequently, but hard liquor only occasionally. One smoker and two nonsmokers were nondrinkers.

The alcohol samples were prepared from reagent grade, 95\% ethyl alcohol (EtOH) and freshly distilled unchlorinated water. Using a paired comparison method of differential sensitivity described in detail previously (Pangborn et al, 1967), Ss evaluated eight paired comparisons consisting of $8 \% \mathrm{EtOH}$ vs $4 \%, 5 \%, 6 \%, 7 \%$, $9 \%, 10 \%, 11 \%$, and $12 \% \mathrm{EtOH}(\mathrm{v} / \mathrm{v})$ at room temperature $\left(21^{\circ} \pm 1^{\circ} \mathrm{C}\right)$. Concentrations were selected by prior screening to represent readily recognizable but not overly intense alcohol levels. Pairs within a set of eight and samples within a pair were presented in randomized counterbalanced order. Ss received approximately $30-\mathrm{ml}$ portions in $50-\mathrm{ml}$ beakers identified by two- or three-digit code numbers and were instructed to circle the number of the sample within each pair with the greater alcohol intensity. Distilled water was used for oral rinsing between pairs and swallowing was not permitted. Ss were seated comfortably in individual partitioned booths maintained at $21^{\circ} \pm 1^{\circ} \mathrm{C}$ and were informed of their results following each test. Cake or cookies were provided as "rewards." Sessions were held from 9:30 to 10:30 a.m. on 6 test days. The first session was considered a practice period and the results were not included in the final data.

\section{RESULTS AND DISCUSSION}

The percent correct response to individual paired samples of EtOH are shown in Table 1, subdivided according to before and immediately after smoking a cigarette and for the first and second set for the nonsmokers. Application of analysis of variance to the individual frequencies of correct responses gave a significant $F$ ratio for alcohol concentration only. No significance could be attributed to groups (smokers vs nonsmokers), sets (before vs after or Set 1 vs Set 2), replications, or any of the double and triple interactions.

A regression line was calculated to fit each set of data in order to determine the just noticeable differences (jnd) and the points of subjective equality (pse) reported in Table 2. Five smokers showed slightly increased sensitivity to ethanol after smoking, four decreased their sensitivity by smoking, and one showed no change. The increased sensitivity could be a direct result of smoking, since tobacco might have sensitized the tongue to the burning irritation of the alcohol. However, this

Table 1

Correct Responses of Smokers and Non-Smokers to Concentrations of Ethyl Alcohol. ( $\mathrm{N}=50)$

\begin{tabular}{lrrrrrrrrr}
\hline Alcohol Comparison: 8 vs & 4 & 5 & 6 & 7 & 9 & 10 & 11 & $12 \%$ \\
\hline $\begin{array}{l}\text { Smokers } \\
\quad \text { Before }\end{array}$ & 84 & 90 & 84 & 72 & 62 & 86 & 84 & 96 \\
$\quad$ After & 90 & 90 & 88 & 72 & 76 & 84 & 90 & 90 \\
$\begin{array}{l}\text { Non-Smokers } \\
\text { Set 1 }\end{array}$ & 98 & 90 & 80 & 64 & 66 & 92 & 92 & 98 \\
Set 2 & 96 & 96 & 76 & 76 & 62 & 80 & 96 & 96 \\
\hline
\end{tabular}


Table 2

Correct Responses, Just Noticeable Differences, and Points of Subjective Equality for Ethyl Alcohol

\begin{tabular}{cccc}
\hline & $\begin{array}{c}\% \\
\text { Correct }\end{array}$ & $\begin{array}{c}\text { JND } \\
\% \text { EtOH }\end{array}$ & $\begin{array}{c}\text { PSE } \\
\% \text { EtOH }\end{array}$ \\
\hline 10 Smokers & $\mathbf{8 3 . 6 ^ { \mathrm { a } }}$ & 2.0 & $\mathbf{8 . 2}$ \\
Before Smoking & $\mathbf{8 2 . 3 ^ { \mathrm { b } }}$ & 2.0 & $\mathbf{8 . 1}$ \\
After Smoking & $\mathbf{8 5 . 0 ^ { \mathrm { b } }}$ & 2.0 & $\mathbf{8 . 3 5}$ \\
10 Non-Smokers & $\mathbf{8 4 . 9 ^ { \mathrm { a } }}$ & 1.8 & 7.8 \\
Set 1 & $\mathbf{8 5 . 0 ^ { \mathrm { b } }}$ & $\mathbf{1 . 8}$ & 7.7 \\
Set 2 & $\mathbf{8 4 . 8 ^ { \mathrm { b } }}$ & $\mathbf{1 . 8}$ & $\mathbf{7 . 9}$ \\
\hline
\end{tabular}

\section{a Based on 800 judgments}

$b$ Based on 400 judgments

does not agree with Krut et al's (1961) suggestion that the alkaloids of tobacco smoke may act in a manner similar to quinine and, in this way, possibly fatigue the mechanisms for perception of bitterness, a taste characteristic often attributed to ethanol (Martin, 1970). Number of cigarettes smoked per day and percent correct response were not related. Ethanol sensitivity appeared to be more important than cigarette consumption.

A time-order effect is not suspected here, as the nonsmokers showed no improvement from Set 1 to Set 2, and, in fact, obtained fewer correct responses in five out of eight concentrations presented in the second set. This decrease in correct response might be attributable to fatigue due to the anesthetic action of alcohol on sensory nerve endings (Liebmann \& Panettiere, 1957). There was, however, no significant change in correct responses from the first through the eighth pair within a set: $88 \%, 85 \%, 83 \%, 83 \%, 83 \%$, $86 \%, 84 \%$, and $85 \%$ correct, respectively. Therefore, it seems even less likely that fatigue would be involved between sets, since there was a $10-\mathrm{min}$ rest between the first and second testing.

Slightly higher overall correct responses and correspondingly smaller jnds were obtained for the 10 nonsmokers as compared to the 10 smokers. The pse values average $0.2 \%$ greater than the $8.0 \%$ standard for the smokers and $0.2 \%$ less for the nonsmokers, a result of the steeper regression line for the latter group owing to their higher overall correct response.

The jnds of $1.8 \%$ to $2.0 \%$ EtOH agree with detectable concentration differences for $\mathrm{p}=0.001$ reported by Berg et al (1955) of $1.2 \%, 1.5 \%$, and $2.4 \%$, respectively, for concentrations of $4.0 \%, 8.0 \%$, and $12.0 \%$ ethanol.

The results obtained herein for EtOH substantiate the previous conclusion from this laboratory that oral sensitivity is unchanged immediately after cigarette smoking. Nonetheless, there might be merit in requiring $S s$ to refrain from smoking for up to $30 \mathrm{~min}$ prior to entering a test room where the smoke odor could distract nonsmokers.

\section{REFERENCES}

BERG, H. W., FILIPELLO, F., HINREINER, E. \& WEBB, A. D. Evaluation of thresholds and minimum difference concentrations for various constituents of wines. 1. Water solutions of pure substances. Food Technology, 1955, 9, 23-26.

HELLEKANT, G. Action and interaction of ethyl alcohol and some other substances on the receptors of the tongue. In $T$. Hayashi (Ed.), Olfaction and taste II. Oxford and New York: Pergamon Press, 1967. Pp. 465-479.

KAPLAN, A. R., GLANVILLE, E. V., \& FISCHER, R. Taste threshold for bitterness and cigarette smoking. Nature, 1964, 202, 1366.

KR UT, L. H., PERRIN, M. J., \& BRONTE-STEWART, B. Taste perception in smokers and nonsmokers. British Medical Journal, 1961, 1, 384-387.

LIEBMANN, A. J., \& PANETTIERE, B R. Quality control and consumer testing for distilled alcoholic beverages. Wallerstein Laboratory Communications, 1957, 29, 27-39.

MARTIN, S. Influence of alcohol on gustatory, salivary and oral thermal responses. Unpublished Master's thesis, University of California, Davis, 1970.

MONCRIEFF, R. W. Sensory discrimination and smoking. Food Processing \& Marketing, 1968 , 37, 303-305.

PANGBORN, R. M., TRABUE, I. M., \& PIKIELNA, N. B. Taste, odor, and tactile discrimination before and after smoking. Perception \& Psychophysics, 1967, 2, 529-532.

\section{NOTES}

1. Supported in part by the Council for Tobacco Research -U.S.A.

2. Address: Department of Food Science \& Technology, University of California, Davis, California 95616.

(Accepted for publication December 3, 1969.) 